\title{
A FORMAÇÃO DOCENTE DE PROFESSORES QUE ENSINAM MATEMÁTICA: UM ESTUDO A PARTIR DAS NARRATIVAS DE "PIBIDIANOS"
}

\author{
Graziela Rodrigues Lucas ${ }^{1}$ \\ Maira Bartira Kaufmann ${ }^{2}$ \\ Cláudio José de Oliveira ${ }^{3}$
}

\section{RESUMO}

O presente artigo apresenta e discute os resultados da pesquisa Identidade e Diferença na Formação Docente, que teve como objetivo geral entender e problematizar a formação docente de professores que ensinam matemática na Educação Básica - EB, a partir das narrativas de bolsistas do Programa Institucional de Bolsas de Iniciação à Docência - PIBID. O referencial teórico é concebido, principalmente, a partir dos estudos de Maria Manuela Alves Garcia e Gelsa Knijnik. Para a produção dos dados, realizamos entrevistas coletivas no formato de Grupos de Discussão - GD. A análise dos dados, realizada com base na transcrição dos GDs e nos registros do diário de campo, resultou na produção de três unidades analíticas, a saber: "o foco das ações dos 'pibidianos' está centrado na falta, e não nas possibilidades"; "a maioria dos alunos tem dificuldade na matemática escolar"; "a existência de uma relação entre teoria e prática". Assim, ao pensarmos nas experiências vivenciadas pelos acadêmicos no PIBID, é possível inferir que elas contribuem para a sua formação docente, ainda que necessitem ser mais bem problematizadas.

Palavras-chave: Formação Docente. Educação Matemática. Narrativas. PIBID.

\begin{abstract}
This paper presents and discusses the results of the research called Identity and Difference in Teacher Education, which aimed at understanding and problematizing mathematics teacher education in Basic School - BS by considering the narratives of participants in the Institutional Scholarship Program of Teacher Induction - PIBID. The theoretical references were mainly based on studies by Maria Manuela Alves Garcia and Gelsa Knijnik. Data were produced in collective interviews performed as Discussion Groups - DGs. The data analysis, carried out through both the transcription of DGs and field notes, resulted in the production of three analysis units as follows: "the focus of 'pibidians' narratives is centered on lack, rather than on possibilities"; "most students have difficulties in school mathematics"; "existence of a relationship between theory and practice". Thus, by thinking about the experiences lived by PIBID students, it is possible to infer that they have contributed to their education, although such experiences still require further problematization.
\end{abstract}

Keywords: Teacher Education. Mathematical Education. Narratives. PIBID.

\footnotetext{
${ }^{1}$ Acadêmica do Curso de Psicologia da Universidade de Santa Cruz do Sul - UNISC. <glucas@mx2.unisc.br>.

${ }^{2}$ Acadêmica do Curso de Pedagogia da Universidade de Santa Cruz do Sul - UNISC. <mairakaufmann@hotmail.com>.

${ }^{3}$ Doutor em Educação, professor pesquisador no Departamento de Educação e no Programa de Pós-Graduação em Educação da Universidade de Santa Cruz do Sul - UNISC. <coliveir@unisc.br>.
} 


\section{INTRODUÇÃO}

O presente artigo apresenta discussões acerca dos estudos sobre a pesquisa "Identidade e Diferença na Formação Docente" a qual teve como objetivo geral entender e problematizar a formação docente de professores que ensinam matemática na Educação Básica - EB. O estudo teve como eixo central a discussão das narrativas de bolsistas "pibidianos" a respeito dos processos de aprender e ensinar matemática na EB. O grupo dos sujeitos foi constituído por acadêmicos dos Cursos de Pedagogia e Matemática, os quais atuavam como bolsistas no Programa Institucional de Bolsas de Iniciação à Docência - PIBID em uma escola estadual de ensino médio de Santa Cruz do Sul.

No primeiro momento reunimos informações sobre o PIBID, programa criado no ano de 2007 a partir de uma ação conjunta do Ministério da Educação - MEC, da Coordenação de Aperfeiçoamento de Pessoal de Nível Superior - CAPES e do Fundo Nacional de Desenvolvimento da Educação - FNDE. O programa concede bolsas a alunos de licenciatura com o intuito de promover a inserção desses estudantes no contexto das escolas públicas desde o início da sua formação acadêmica. Seus principais objetivos são: incentivar a formação de docentes para atuar na EB; contribuir para a valorização do magistério; inserir os licenciandos na rotina das escolas públicas, proporcionando-lhes experiências metodológicas; promover a integração entre Educação Superior e a EB; e contribuir para a articulação entre teoria e prática necessárias à formação dos docentes, elevando a qualidade das ações acadêmicas nos cursos de licenciatura (CAPES, 2012).

A Universidade de Santa Cruz do Sul - UNISC iniciou sua participação no PIBID em 2010, com um projeto intitulado "Professor em formação: tecendo possibilidades pedagógicas”. Em dois anos de execução, o projeto já contou com a participação de dez escolas públicas de Santa Cruz do Sul e aproximadamente trezentos bolsistas de iniciação à docência, os quais dividiram-se em doze subprojetos: Pedagogia, Matemática, Educação Física, Letras/Português, Letras/Espanhol, Letras/Inglês, Licenciatura em Computação, Química, Biologia, História, Geografia e Filosofia.

O PIBID/UNISC foi estruturado com base no conceito de redes de aprendizagem, que considera ser indispensável a existência de uma interação entre estudantes de licenciatura, profissionais técnico-administrativos da universidade, coordenadores dos subprojetos e professores supervisores das escolas participantes. Assim, o programa parte do pressuposto que essas redes de aprendizagem "fortalecem a universidade e a escola enquanto espaços abertos e conectados com o mundo e o professor enquanto pesquisador e autor de projetos 
educativos concernentes com as demandas da atualidade" (ABREU; LANZARINI, 2013, p. $4)$.

\section{FUNDAMENTAÇÃO TEÓRICA}

As discussões realizadas neste artigo se situam nas formulações de dois conceitoschave do presente estudo, isto é, Formação Docente e Educação Matemática. Entendemos que foi a partir da investigação e articulação desses conceitos que conseguimos dar um ponto de partida ao trabalho analítico que pretendíamos empreender.

Valendo-nos, então, da definição dada por Jennifer Gore e Pablo Manzano (1996), concebemos a Formação Docente como aquela que "se ocupa de enseñar a las personas a como enseñar" (1996, p. 165). De fato, como bem aponta Garcia (2002), podemos caracterizá-la como um espaço atravessado por discursos pedagógicos, os quais contribuem para a estruturação de determinadas práticas e identidades professorais. Essas práticas, por sua vez, instituem formas particulares de desempenho, competências e modos de ser, sendo que, quando internalizadas por professores ou futuros professores, acabam regulando e disciplinado a categoria docente.

Segundo Garcia, Hypolito, Vieira (2005) e Hardt (2006), os diferentes espaços de formação de professores podem ser problematizados como lugares onde se inventam práticas e maneiras corretas de se tornar um "bom" profissional. Para os autores, são espaços de relações de poder que promovem a disciplinarização, a regulação e a normalização discursiva, engessando o processo de formação no sentido do instrumentalizar os professores a exercerem as normas definidas, colocando em funcionamento formas específicas de subjetivação do sujeito (HARDT, 2006). Assim, a questão da Formação Docente fica restrita à receber “orientações" externas sem o sujeito professor participar do processo. O sujeito da prática é posicionado como aquele que executa tarefas, mas não pensa e age sobre elas. Esse assujeitamento do professor percorre não só a formação inicial como também nas propostas de cursos, fóruns, seminários e materiais didáticos disponíveis para a consulta dos docentes.

Quando nos referimos à Educação Matemática, por sua vez, pensamos na possibilidade de existência de muitas matemáticas, o que torna possível problematizar o discurso da matemática escolar que a legitima como única, universal, branca, urbana, eurocêntrica e masculina (KNIJNIK; WANDERER, 2013). De fato, entendemos que isto que usualmente chamamos de matemática talvez seja um modo muito particular de raciocinar, de 
pensar o mundo, o qual muitas vezes é colocado como única forma de "ser inteligente" nas escolas ou até mesmo nos cursos de formação de professores. Para Knijnik e Wanderer, operar com estas ideias nos permite problematizar as matemáticas escolar e acadêmica envolvidas com a "produção das relações de poder-saber e com a constituição de regimes de verdade" (2007, p. 12). Deste modo, na pesquisa realizada, problematizamos a utilização da matemática escolar como "régua" na comparação com outros modos de se pensar matematicamente, não permitindo que possamos dar visibilidade nos currículos às matemáticas escondidas nos afazeres cotidianos.

\section{PROCEDIMENTOS METODOLÓGICOS}

Para a produção dos dados da pesquisa, realizamos entrevistas coletivas no formato de Grupos de Discussão - GD, conforme apontamentos de Silva (2008), Lervolino, Pelicione (2001) e Duarte (2004). Podemos inferir que a técnica do GD é baseada na interação que acontece entre os componentes do grupo, que possui como moderador da discussão o pesquisador. Segundo Silva (2008, p. 41) é uma "técnica qualitativa que visa o controle da discussão de um grupo de pessoas [...], privilegia a observação e o registro de experiências e reações dos indivíduos participantes do grupo". Nesse mesmo sentido, Lervolino e Pelicione (2001, p. 116) escrevem que "é desenvolver um processo, que contém procedimentos que visam a compreensão das experiências do grupo participante, do seu próprio ponto de vista."

Dessa forma, o grupo dos sujeitos da pesquisa foi composto por quatro acadêmicos do Curso de Pedagogia e três acadêmicos do Curso de Matemática da UNISC, os quais atuavam como bolsistas do PIBID em uma escola estadual de ensino médio de Santa Cruz do Sul. As sessões do GD ocorreram em quatro datas, com duração de 60 minutos cada uma, destacando que apenas os sujeitos e os pesquisadores estiveram presentes. A produção de dados ocorreu com base nas anotações do diário de campo e na transcrição das entrevistas coletivas produzidas a cada encontro.

A análise do material da pesquisa foi realizada com aproximações aos estudos realizados por Gelsa Knijnik e Cláudia Glavam Duarte (2010); Gelsa Knijnik e Juliana Schreiber (2012); Gelsa Knijnik e Fernanda Wanderer (2013); Sabrina Oliveira e Gelsa Knijnik (2011); Marli Teresinha Quartieri (2012); Valerie Walkerdine (2007, 2010); e, Cláudio José de Oliveira (2010, 2013). 


\section{RESULTADOS E DISCUSSÃO}

$\mathrm{Na}$ análise do material emergiram três unidades analíticas, a saber: "o foco das ações dos 'pibidianos' está centrado na falta e não nas possibilidades"; "a maioria dos alunos tem dificuldade na matemática escolar"; "a existência de uma relação entre teoria e prática". Para a discussão dessas questões selecionamos alguns excertos ${ }^{4}$ das entrevistas coletivas, os quais permitiram colocar em pauta a proposta deste artigo.

É importante destacar, ainda, que em consonância aos estudos de Knijnik e Duarte (2010), nossa pesquisa não teve a intenção de questionar a validade ou não dos excertos analisados ou, "em um sentido mais amplo, estilhaçar 'verdades' e substituí-las por outras que seriam ‘mais adequadas’ para a área da Educação Matemática” (p. 867). Da mesma forma, não nos interessamos pelos sentidos ocultos que pudessem estar presentes nas enunciações, mas pelo contrário, buscamos "lê-1[a]s em suas exterioridades" (KNIJNIK; DUARTE, 2010, p. 870) de modo que fosse possível pensar diferentemente sobre aquilo que está legitimado na docência desse grupo de professores que ensina matemática na EB.

No que tange a primeira unidade analítica, as narrativas evidenciam uma grande preocupação por parte dos bolsistas em relação à confecção de materiais instrucionais, ao planejamento de oficinas e ao desenvolvimento de atividades que estejam direcionadas aos alunos nomeados com “dificuldades em matemática”, os quais, segundo Oliveira (2013), são geralmente posicionados como o "outro" da sala de aula, os sujeitos que precisam "se esforçar mais", "ter maior concentração" ou fazer "corretamente" os exercícios conforme as técnicas e algoritmos ensinados pelos professores.

[...] daí nós chegamos nas escolas e os supervisores e as professoras chegaram e disseram pra nós trabalhar com os alunos que estavam com dificuldades no final do ano, como oficinas de reforço. (grifos nossos).

Eu não tô usando mais a adição, porque eu percebi que eles não tinham dificuldades. Porque a gente faz, na verdade, no início sondagens, né. E na matemática, então, a adição era mais fácil. Então, agora, por enquanto, eu estou trabalhando a subtração. (grifos nossos).

Ocorre, muitas vezes, que acontece uma ruptura do modo que o professor atua na aula e como os "pibidianos" trabalham. O PIBID foca seu trabalho nas dificuldades dos alunos, utilizando atividades lúdicas, jogos, e atividades diferenciadas, para tentar mudar a aversão que muitos alunos ainda têm da matemática. Pois, a matemática exige concentração e a maioria não tem hábito de ler e interpretar, o que é indispensável para um bom crescimento intelectual e pessoal. (grifos nossos).

\footnotetext{
${ }^{4}$ Os excertos são apresentados em itálico à margem direita no corpo do texto.
} 
A partir disso, a gente fazia as nossas atividades. Não que ela [a supervisora do PIBID] dissesse "ah, você tem que trabalhar isso", não. Ela dizia "que bom vocês trabalharem isso", porque eles tem mais dificuldade. (grifos nossos).

As narrativas supracitadas também reforçam uma ideia de que as matemáticas acadêmica e escolar traduzem um sonho de pureza, ordem e razão. De fato, "os processos de ensinar e aprender matemática usualmente estão centrados na análise da 'falta' dos alunos: falta de raciocínio, falta de atenção, não sabe pensar direito etc.” (OLIVEIRA, 2013, p. 7), o que restringe o campo de ação dos professores aos conteúdos que os alunos "ainda não sabem”, sem reconhecer aquilo que eles já sabem ou têm curiosidade em aprender.

Para Quartieri (2012), todavia, a curiosidade é um fator fundamental para os processos de aprendizagem. Baseada nas teorizações do filósofo Decroly, a autora defende a ideia de que a Educação Matemática deve ser orientada pelos interesses do próprio discente, uma vez que é a partir da investigação de situações-problema da sua escolha que ele é estimulado a entrar em contato com a sua realidade física e social e, consequentemente, a desenvolver "um conhecimento mais crítico e reflexivo acerca dos conteúdos da matemática escolar" (2012, p. 8).

Ao deslocar a discussão para o contexto do presente estudo é possível que façamos alguns questionamentos: de que forma as práticas pedagógicas dos bolsistas "pibidianos" incorporam os interesses daqueles para as quais elas se dirigem? Como se dá a participação dos discentes na escolha dos conteúdos desenvolvidos nas oficinas? As atividades são pensadas para os alunos ou com eles? Como superar o modelo de "oficina-reforço" utilizado e apostar em ações inovadoras quando os objetivos do PIBID justamente preveem o incentivo de experiências metodológicas e práticas docentes que "busquem a superação de problemas identificados no processo de ensino-aprendizagem" (CAPES, 2012, grifo nosso)?

A análise dos excertos acima ainda nos possibilita outra problematização. As várias enunciações que se referem às dificuldades do aluno na matemática escolar demonstram a existência de "tensionamentos" no modo como esta é usualmente trabalhada em sala de aula ou seja, com base em técnicas rígidas que desconsideram outras maneiras de lidar e manejar os conhecimentos matemáticos que circulam em nosso cotidiano (OLIVEIRA, 2010). Debateremos melhor essa questão a partir da nossa segunda unidade analítica.

O Paulo ${ }^{5}$ [se referindo a um aluno] tinha a tabuada pronta debaixo da mesa. E eu não tinha visto. Só que a tabuada não era só multiplicação, tinha 1 mais 1,1 mais 2 ,

\footnotetext{
${ }^{5} \mathrm{O}$ nome do aluno foi substituído.
} 
sabe. E o que aconteceu, né, vamos supor assim, 186 menos 194, tem que pedir emprestado [nesse momento ela montou a continha na classe para nos explicar]. Para ele ficava igual. (grifos nossos).

Tem dificuldade, mas, às vezes, ela é escolar. Dificuldade naquele conteúdo, naquela determinada... [...] Daí já entrei numa outra discussão, né. (grifos nossos).

Porque, às vezes, eles [alunos] perguntam: "Professora, tô trabalhando tal conteúdo e não serve pra nada". Daí a gente meio que tenta trazer: "Não, isso está presente em tal, tal e tal lugar, por exemplo, nas formas geométricas". Enfim, a gente tenta mostrar no dia a dia, onde eles podem encontrar isso, onde eles vão poder usar isso, onde eles usam a matemática sem perceber. A gente tenta trazer isso, situações assim, que na sala de aula a professora fala que não dá tempo. (grifos nossos).

Em uma proposta de estudo semelhante à nossa, Knijnik e Silva (2008) realizaram Grupos de Discussão com estudantes do ensino médio no intuito de problematizar o enunciado "aprender matemática é difícil". De fato, a análise desse material evidenciou que a dificuldade em aprender a matemática escolar se deve ao formalismo e à abstração dessa área do conhecimento que, ao investir prioritariamente no ensino e na realização do cálculo em si, não desafia os alunos a avaliar e significar o resultado final dos problemas. Ainda segundo as autoras, o que se pretende é justamente a "universalização" do raciocínio lógico, isto é, fazer com que todos os alunos passem "a resolver os exercícios do mesmo modo usando os algoritmos, os símbolos, as regras e as fórmulas ensinadas na escola” (p. 71).

Por outro lado, uma das vertentes da Educação Matemática, a Etnomatemática, desenvolvida por D'Ambrosio em meados da década de 70, considera que é por meio da cultura que atribuímos significados às nossas vidas, em particular, às nossas formas de raciocinar matematicamente. Ao apontar a existência de estreitas relações entre cultura e matemática, ela argumenta sobre a "relevância de que não somente o que é legitimado no Ocidente como ciência matemática [...] [seja] considerada como merecedora de atenção nos processos de escolarização" (KNIJNIK; SILVA, 2008, p. 63). Muito mais que estudar "as matemáticas" das diversas etnias, essa vertente propõe exaltar as diferentes maneiras, técnicas e habilidades de explicar, entender e lidar com os distintos contextos naturais e socioeconômicos da realidade (D’AMBROSIO, 2010).

Segundo Duarte (2009), um enunciado que circula de forma recorrente (e naturalizada) no pensamento etnomatemático diz respeito à importância de trabalhar a "realidade" do aluno como forma de significação dos conteúdos matemáticos. De fato, uma possível leitura a ser feita das narrativas acima nos sugere que é exatamente o não estabelecimento dessas conexões entre o currículo escolar e a "vida real" o que gera o desinteresse e "mau desempenho" do aluno na matemática. Questiona-se, então, até que ponto 
os professores, neste caso os "pibidianos", são "provocados" durante a graduação para "desencadear diferentes possibilidades de ensino-aprendizagem envolvendo ações que considerem contextos sócio-culturais específicos" (BELLO, 2010, p. 377). E, ainda, de que maneira o PIBID contribui para uma formação docente menos formal e mais voltada para a criação de "práticas docentes de caráter inovador" (CAPES, 2012)?

$\mathrm{Na}$ análise do material da pesquisa ainda emergiu uma terceira unidade analítica, isto é, a existência de uma relação entre teoria e prática. De fato, as várias enunciações presentes nas narrativas dos "pibidianos" indicam a existência de um diálogo entre a formação que é obtida na universidade e as oficinas que são a desenvolvidas pelo PIBID, o que reforça a ideia de que as percepções desses acadêmicos são qualificadas na medida em que experienciam a aproximação da vida acadêmica com a vida da escola.

Pra mim está sendo uma experiência em sala de aula, de realidade escolar, de lidar com alunos surdos, de planejar aulas, que eu nunca... Uma coisa é estudar matemática, e outra coisa é planejar matemática e pensar como que eu vou ensinar, como que eи vou trabalhar isso. (grifos nossos).

A prática [na Universidade] é no $7^{\circ}$ e $8^{\circ}$ semestre, né, que é os estágios. [...] Tu não cria experiência em três semanas na educação infantil e três semanas em séries iniciais. Então o PIBID proporciona tudo isso, né. Toda essa experiência profissional pra gente. Tenho que dizer que só acrescenta, né. (grifos nossos).

Até depois para o estágio fica mais fácil né, por que a gente tem que fazer projeto, plano de trabalho. Mesmo que nós tenhamos a teoria, nós ganhamos experiência no PIBID e depois utilizamos tudo isso. (grifos nossos).

O PIBID leva a gente mais pra perto da prática da Pedagogia, né, é uma coisa que o Curso oferece só durante o estágio, que é esse contato direto com as escolas, puder estar na sala de aula. (grifos nossos).

De acordo com D’Ambrosio (2002), todo professor em início de carreira incorpora à sua prática docente experiências que teve ao longo de sua formação, ou seja, aquilo que viu outros professores fazendo, as técnicas e dinâmicas que aprendeu durante as aulas etc. Todavia, na medida em que vai lecionando e adotando uma postura crítica sobre sua própria prática, ele passa a aprimorá-la e, em consequência disso, passa a alimentar novas teorizações que irão novamente produzir mudanças. Eis que é a partir desse elo entre teoria e prática que, segundo o autor, produzimos pesquisa.

[...] um princípio básico das teorias de conhecimento nos diz que as teorias são resultado das práticas. Portanto, a prática resultante da pesquisa modificará ou aprimorará a teoria de partida. E assim modificada ou aprimorada essa teoria criará necessidade e dará condições de mais pesquisa, com maiores detalhes e profundidade, o que influenciará a teoria e a prática. Nenhuma teoria é final, assim como nenhuma prática é definitiva, e não há teoria e prática desvinculadas (D’AMBROSIO, 2002, p. 81). 
Quando pensamos nas experiências dos bolsistas no PIBID, é possível evidenciar em suas narrativas toda a positividade que o programa representa para a sua formação enquanto docentes, visto que os aproxima "pra perto da prática, da realidade escolar”, da tão aguardada "experiência profissional”. À universidade, entretanto, é reservada a função de "preparadora", isto é, o lugar onde se encontram as teorias que subsidiarão toda e qualquer prática em sala de aula. Tendo em vista o que foi dito, questionamos: de que forma o PIBID estimula não apenas a inserção dos licenciandos no cotidiano das escolas (CAPES, 2012), mas a problematização das práticas docentes nelas legitimadas? Ou melhor: de que forma essa integração entre Ensino Superior e Educação Básica contribui para a formação de docentes menos "transmissores" e mais "produtores" de conhecimento e novas pesquisas? Neste sentido, concordamos com Garcia (2002) quando esta diz:

\begin{abstract}
A produção/fabricação de docentes reflexivas/os, capazes de examinar, regular e modificar constantemente as próprias práticas, implica na produção de si mesmas/os enquanto seres capazes de examinarem-se, regularem-se e modificarem-se a si próprias/os no contexto dessas práticas. E, implica ainda, na produção de uma ideia do que é auto-conhecimento, auto-integridade, do que é ser sujeito de suas próprias ações [...] (p. 161).
\end{abstract}

Assim, ao pensarmos nas experiências vivenciadas pelos acadêmicos no PIBID, é possível inferir que elas contribuem para a sua formação docente, embora necessitem ser mais bem problematizadas, no sentido de "desacomodar" determinadas práticas (legitimadas) nos processos que envolvem o ensino e a aprendizagem da matemática na EB.

\title{
5 CONSIDERAÇÕES FINAIS
}

Ao finalizar este texto sublinham-se outros caminhos investigativos que emergiram do material analisado. Os docentes em formação, que também podem ser nomeados como os sujeitos da pesquisa, deixam muitas interrogações sobre a formação docente, em especial, sobre os processos que tangenciam os conhecimentos matemáticos. Aprender e ensinar a matemática escolar é muito mais que seguir os algoritmos consagrados nos materiais didáticos, que passam de geração em geração como parâmetro que determina e nomeia os "gênios" no raciocínio lógico. Sem dúvida de que "dominar" certos algoritmos se faz importante, porém, não é suficiente para avaliarmos os estudantes como "bons" ou "ruins" na matemática. 
Outra questão que emergiu do material analisado é a necessária imbricação dos resultados da investigação com outras áreas do conhecimento. Neste sentido, uma das primeiras repercussões dos resultados encontrados foi o desenvolvimento do projeto de pesquisa "Linguagem e Educação Matemática para a Educação Básica: um estudo de experiências pedagógicas", que pretende investigar a formação de professores em escolas da EB, enfocando os processos envolvidos nas atividades de linguagem e de educação matemática.

Deste modo, finalizamos estes escritos deixando as portas abertas para outras interrogações e respostas, pensando que o caminho poderia ter sido outro, mas, pelas opções que fizemos, encontramos menos respostas definitivas e, sim, dúvidas permanentes.

\section{REFERÊNCIAS}

ABREU, R. S. de; LANZARINI, J. N. PIBID/UNISC: educação presencial e a distância integrando reflexão, teoria e prática na formação de professores. In: $19^{\circ}$ CONGRESSO ABED DE EDUCAÇÃO A DISTÂNCIA, Salvador - BA, 2013. Anais... Disponível em: <http://www.abed.org.br/congresso2013/trabalhos/APRESENTACOES_SESSOES_PARAL ELAS-horarios.pdf >. Acesso em: 28 fev. 2014.

BELLO, S. E. L. Etnomatemática e sua relação com a formação de professores: alguns elementos para discussão. In: KNIJNIK, G.; WANDERER, F.; OLIVEIRA, C. J. de (Orgs.). Etnomatemática: currículo e formação de professores. Santa Cruz do Sul: EDUNISC, 2010. CAPES. Coordenação de Aperfeiçoamento de Pessoal de Nível Superior, 2012. Disponível em: 〈http://www.capes.gov.br/educacao-basica/capespibid〉. Acesso em: 10 nov. 2014.

D’AMBROSIO, U. Educação Matemática: da teoria à prática. 9 ed. São Paulo: Papirus Editora, 2002.

Etnomatemática e educação. In: KNIJNIK, G.; WANDERER, F.; OLIVEIRA, C. J. de (Orgs.). Etnomatemática: currículo e formação de professores. Santa Cruz do Sul: EDUNISC, 2010.

DUARTE, C. G. A "realidade" nas tramas discursivas da Educação Matemática Escolar. 2009. 198 f. Tese (Programa de Pós-Graduação em Educação) - Universidade do Vale do Rio dos Sinos, São Leopoldo, 2009.

DUARTE, R. Entrevistas em pesquisas qualitativas. Educar, n. 24, p. 213-225, 2004.

GARCIA, M. M. A. A docência no discurso das pedagogias críticas. In: HYPOLITO, Á. M.; VIEIRA, J. dos S.; GARCIA, M. M. A. (Orgs.). Trabalho docente: formação e identidades. Pelotas: Seiva, 2002.

GARCIA, M. M. A.; HYPOLITO, Á. M.; VIEIRA, J. S. As identidades docentes como fabricação da docência. Educação e Pesquisa, São Paulo, v. 31, n. 1, p. 45-56, 2005. 
GORE, J. M.; MANZANO, P. Controversias entre las pedagogías: discursos críticos y feministas como regímenes de verdad. Madrid: Morata; La Coruña: Paideia, 1996.

HARDT, L. S. Formação de professores: as travessias do cuidado de si. In: $29^{a}$ REUNIÃO ANUAL DA ANPED, Caxambu - MG, 2006. Anais... Disponível em: <http://29reuniao.anped.org.br/trabalhos/trabalho/GT08-1764--Int.pdf $>$. Acesso em: 15 out. 2012.

KNIJNIK G.; DUARTE, C. G. Entrelaçamentos e dispersões de enunciados no discurso da Educação Matemática Escolar: um estudo sobre a importância de trazer a "realidade" do aluno para as aulas de matemática. Bolema, v. 23, n. 37, p. 863-886, 2010.

KNIJNIK G.; SCHREIBER, J.. Educação Matemática em cursos de Pedagogia: um estudo com professores brasileiros dos anos iniciais de escolarização. $R L E$, v. 5, p. 4-20, 2012.

KNIJNIK, G.; SILVA, F. B. de S. da. "O problema são as fórmulas": um estudo sobre os sentidos atribuídos à dificuldade em aprender matemática. Caderno de Educação, n. 30, p. 63-78, 2008.

KNIJNIK, G.; WANDERER, F. Os (entre) lugares dos materiais concretos no currículo escolar: problematizando verdades sobre a educação matemática de pessoas adultas camponesas. In: V CONGRESSO INTERNACIONAL DE EDUCAÇÃO: PEDAGOGIAS (ENTRE) LUGARES E SABERES. Anais... Pelotas: Seiva Editora, 2007.

Programa Escola Ativa, escolas multisseriadas do campo e Educação Matemática. Educação e Pesquisa, v. 39, n. 1, p. 211-215, 2013.

LERVOlinO, S. A.; PELICIONE, M. C. A utilização do grupo focal como metodologia qualitativa na promoção da saúde. Revista da Escola de Enfermagem, v. 35, n. 2, p. 115-121, jun. 2001.

OLIVEIRA, C. J. de. As contribuições do PIBID para a formação docente de professores que ensinam matemática. In: 36 ${ }^{\mathbf{a}}$ REUNIÃO NACIONAL DA ANPED. Goiânia - GO, 2013. Anais... Disponível em: <http://36reuniao.anped.org.br/trabalhos/177-trabalhos-gt19educacao-matematica $>$. Acesso em: 16 fev. 2014.

Práticas etnomatemáticas no cotidiano escolar: possibilidades e limitações. In: KNIJNIK, G.; WANDERER, F.; OLIVEIRA, C. J. de (Orgs.). Etnomatemática: currículo e formação de professores. Santa Cruz do Sul: EDUNISC, 2010.

OLIVEIRA, S.; KNIJNIK, G.. Educação Matemática e jogos de linguagem da forma de vida rural do município de Santo Antônio da Patrulha: um estudo sobre o medir a terra e suas unidades de medida. Boletim GEPEM, v. 59, p. 62-72, 2011.

QUARTIERI, M. T. A mobilização do interesse do aluno no discurso sobre a Modelagem Matemática Escolar. In: 35 ${ }^{\text {a }}$ REUNIÃO NACIONAL DA ANPED. Porto de Galinhas - PE, 2012. Anais... Disponível em: <http://35reuniao.anped.org.br/images/stories/trabalhos/GT19\%20Trabalhos/GT191426_int.pdf $>$. Acesso em: 26 jul. 2013. 
SILVA, F. B. de S. da. "A(prender) matemática é difícil”: problematizando verdades do currículo escolar. 2008. 118 f. Dissertação (Programa de Pós-Graduação em Educação) Universidade do Vale do Rio dos Sinos, São Leopoldo, 2008.

WALKERDINE, V. Ciência, razão e a mente feminina. Educação \& Realidade. v. 32, n. 1, p. 7-24, 2007.

Diferença, cognição e Educação Matemática. In: KNIJNIK, G.; WANDERER, F.; OLIVEIRA, C. J. de (Orgs.). Etnomatemática: currículo e formação de professores. Santa Cruz do Sul: EDUNISC, 2010. 